\title{
Early experience of uniportal video assisted thoracoscopic surgery in a New Thoracic Unit in Hospital Kuala Lumpur, Malaysia
}

\author{
Narasimman Sathiamurthy¹, Nguk Chai Diong ${ }^{2}$, Benedict Dharmaraj² \\ ${ }^{1}$ Consultant Thoracic \& General Surgeon, Thoracic Unit, Hospital Kuala Lumpur, Kuala Lumpur 505860, Malaysia. \\ ${ }^{2}$ Thoracic Fellow, Hospital Kuala Lumpur, Thoracic Unit, Hospital Kuala Lumpur, Kuala Lumpur 505860, Malaysia.
}

Correspondence to: Dr Narasimman Sathiamurthy, Consultant Thoracic \& General Surgeon, Thoracic Unit, Hospital Kuala Lumpur, Kuala Lumpur 505860, Malaysia. E-mail: drnara@hotmail.com

How to cite this article: Sathiamurthy N, Diong NC, Dharmaraj B. Early experience of uniportal video assisted thoracoscopic surgery in a New Thoracic Unit in Hospital Kuala Lumpur, Malaysia. Mini-invasive Surg 2020;4:38.

http://dx.doi.org/10.20517/2574-1225.2020.25

Received: 21 Feb 2020 First Decision: 4 Mar 2020 Revised: 30 Mar 2020 Accepted: 12 May 2020 Published: 18 Jun 2020

Science Editor: Noriyoshi Sawabata Copy Editor: Jing-Wen Zhang Production Editor: Tian Zhang

\begin{abstract}
The evolution of video technology and instrumentation have revolutionised the way lung resections are performed without compromising outcomes. In a new thoracic surgery setup, we have adopted the uniportal video assisted thoracoscopic surgery (U-VATS) technique for lung resections in most of our cases. A retrospective review of operative records from July 2017 till June 2019 in Hospital Kuala Lumpur (HKL) for all thoracic surgeries was done. Patients were divided into two groups: those that underwent U-VATS surgery in the first and second year as part of the learning curve. The operative time, blood loss, lymph node yield, duration of drain placement, and length of hospital stay were compared between the groups. The most common indication for U-VATS surgery was malignant lung tumors (21\%) followed by ruptured bullae (20\%) and empyema thoracis (15\%). The average time taken for lobectomies performed for non-small cell lung cancer was $201 \mathrm{~min}$. U-VATS decortication caused the most amount of blood loss with an average of $350 \mathrm{~mL}$, followed by aspergilloma at $315 \mathrm{~mL}$ and bronchoplasty at $250 \mathrm{~mL}$. The rest of the procedures had $<150 \mathrm{~mL}$ of blood loss. There was no significant difference in the parameters compared between procedures in the two groups. No mortality was seen.The learning curve of U-VATS was used as a guide to gradually increase the complexity of cases performed in a pyramidal manner. U-VATS is an alternative and promising minimal access approach in thoracic surgery that can be safely performed in Malaysia.
\end{abstract}

Keywords: Uniportal, video assisted thoracoscopic surgery, Hospital Kuala Lumpur, early experience

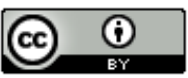

(C) The Author(s) 2020. Open Access This article is licensed under a Creative Commons Attribution 4.0 International License (https://creativecommons.org/licenses/by/4.0/), which permits unrestricted use, sharing, adaptation, distribution and reproduction in any medium or format, for any purpose, even commercially, as long as you give appropriate credit to the original author(s) and the source, provide a link to the Creative Commons license, and indicate if changes were made.

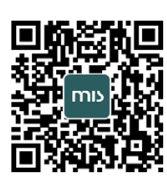




\section{INTRODUCTION}

Since Giancarlo Roviaro performed the first lung resection with video assistance through small incisions without rib spreading in 1992, the evolution of video technology and instrumentation have revolutionised the way lung resections are performed without compromising outcomes ${ }^{[1]}$. Diego Gonzales-Rivas popularised the uniportal video assisted thoracoscopic surgery (U-VATS) technique by demonstrating reproducibility of the surgeries and improving patient outcomes. He also performed many complex procedures like segmentectomies and bronchial and arterial sleeves through U-VATS ${ }^{[2]}$. In a new thoracic surgery setup, we adopted the U-VATS technique for lung resections in most of our cases. This article will describe our experience through the learning curve of adaptating the U-VATS approach in thoracic surgery.

\section{MATERIALS AND METHODS}

Operative records of all thoracic surgeries performed from July 2017 till June 2019 in Hospital Kuala Lumpur (HKL) were retrospectively reviewed. All surgeries were performed by a single thoracic surgeon in a newly established thoracic surgery unit. The unit consists of a thoracic surgeon, two thoracic fellows and a surgical house officer. Indications for surgery were mainly infective pleural diseases and tumors (benign and malignant). This and the surgical approach were explained to the patient in detail and consent was taken both for the procedure itself and its recording.

All surgeries were performed under general anaesthesia with single-lung ventilation using a double-lumen endotracheal tube. All patients were positioned in the right or left lateral position, or supine and then cleaned and square draped. The surgeon and assistant would then stand in front of the patient. A 3 to $4 \mathrm{~cm}$ incision would be made in the 4th or 5th intercostal space, just medial to the anterior axillary line. No rib spreading manoeuvres were required. A wound protector was applied in all cases. A $10 \mathrm{~mm} 30^{\circ}$ telescope with a high definition video system was used in all patients. VATS instruments were used to assist with the surgeries and up to four instruments could be placed through the uniportal access. Resected tumors were removed with an endobag and a $24 \mathrm{Fr}$ chest drain was then inserted through the same incision for noninfective cases. Two drains, a $24 \mathrm{Fr}$ to the apex and a $28 \mathrm{Fr}$ to the base were inserted for infective cases.

A digitally monitored negative pressure closed drainage system (Topaz Medela) was used for all cases. Drains were removed when the amount of effluent was less than $100 \mathrm{~mL}$. All patients were given patientcontrolled anaesthesia with morphine infusion after surgery.

Data analysis was conducted using IBM SPSS Statistics for Windows, Version 21.0 software. The means and standard deviation were calculated for the various parameters. The paired $t$-test was used to compare the means between cases performed in the first and second year after establishment of the unit for the three commonest procedures - bullectomy and pleurodesis, lobectomy and thymectomy.

\section{RESULTS}

From July 2017 to June 2019, 320 thoracic surgeries were performed and 169 (53\%) were U-VATS surgeries. No biportal or multiportal VATS were performed. The mean age of the patients was 41-years and most (104 of 169, 61\%) were males. Amongst the 169 patients, only 57 had no co-morbidities (34\%), while the rest had at least one with the commonest being hypertension followed by diabetes mellitus and previous tuberculosis infection.

The most common indication for U-VATS surgery was malignant lung tumors (21\%) followed by ruptured bullae (20\%) and empyema thoracis (15\%). Malignant lung tumors included non-small cell lung cancer (NSCLC) and lung metastasis [Table 1]. 
Table 1. Patient demographics

\begin{tabular}{ll}
\hline Variables & Number (\%) \\
\hline Age (years \pm SD) & $41 \pm 21.2$ \\
Sex & \\
Male & $104(61)$ \\
Female & $65(39)$ \\
Comorbids & \\
Diabetes mellitus & $27(16)$ \\
Ischemic heart disease & $5(3)$ \\
Hypertension & $31(18)$ \\
ESRF & $5(3)$ \\
COAD & $15(9)$ \\
Previous TB & $17(10)$ \\
Metastatic disease & $12(7)$ \\
No Co-morbidities & $57(34)$ \\
Diagnosis & \\
Empyema thoracis & $25(15)$ \\
Ruptured bullae & $34(20)$ \\
Haemothorax & $11(7)$ \\
Benign lung tumors & $15(9)$ \\
Malignant lung tumors & $36(21)$ \\
Aspergillosis & $9(5)$ \\
Thymic diseases & $25(15)$ \\
Ectopic thyroid/parathyroid & $6(3.5)$ \\
Diaphragmatic eventration & $6(3.5)$ \\
Lung sequestration & $2(1)$ \\
Total & 169 \\
\hline
\end{tabular}

Categorical variables were reported as frequency counts and percentages. ESRF: End stage renal failure; COAD: chronic obstructive airway disease; TB: tuberculosis.

As shown in Table 2, the commonest U-VATS procedure was bullectomy with pleurodesis. This was followed by lobectomy, thymectomy and decortications. The conversion rate to either a biportal VATS or a mini-thoracotomy was $10 \%$. There was no mortality in U-VATS cases.

\section{Operative time}

This varied according to the procedure performed. The average operating time for bullectomy and pleurodesis was $80 \mathrm{~min}$. The longest lobectomy procedure was for aspergilloma, which took $244 \mathrm{~min}$. This is likely because of dense adhesions of the lung to the chest wall and distorted anatomy. Thymectomies were performed via a right U-VATS approach and the average time taken was $147 \mathrm{~min}$.

Comparing the mean operating time between these three procedures in the first and second year, timing is better in the second year but without any significant difference [Table 3].

\section{Blood loss}

U-VATS decortication caused the most amount of blood loss at an average of $350 \mathrm{~mL}$, followed by aspergilloma at $315 \mathrm{~mL}$ and bronchoplasty at $250 \mathrm{~mL}$. In the first year of performing U-VATS lobectomy for aspergilloma, the mean blood loss was higher than that in the second year although there was no significant difference. The rest of the procedures had $<150 \mathrm{~mL}$ of blood loss.

\section{Duration of drain placement and hospital stay}

The duration of drain placement for U-VATS procedures ranged between 1 to 7 days. Infective cases such as empyema thoracis and aspergilloma tend to have a longer duration of drain placement compared to noninfective cases such as bullae, NSCLC and thymectomy. Most patients had their drain removed by postoperative day (POD) 3 when the drain amount was less than $100 \mathrm{~mL}$.

Patients undergoing U-VATS for non-infective causes were usually discharged by POD 3 or 4 . The longest hospital stay was seen in patients with haemothorax, empyema and aspergilloma undergoing U-VATS procedures, which was around 7 days. 
Table 2. U-VATS procedural analysis

\begin{tabular}{|c|c|c|c|c|c|c|c|}
\hline Procedures & Number & $\begin{array}{l}\text { Operative } \\
\text { time (min) }\end{array}$ & $\begin{array}{l}\text { Blood loss } \\
\quad(\mathrm{mL})\end{array}$ & $\begin{array}{l}\text { Lymph } \\
\text { nodes }\end{array}$ & $\begin{array}{l}\text { Conversion to open } \\
\text { thoracotomy }\end{array}$ & $\begin{array}{c}\text { Drain duration } \\
\text { (days) }\end{array}$ & $\begin{array}{l}\text { Hospital stay } \\
\text { (days) }\end{array}$ \\
\hline Biopsy & 11 & 45 & $50 \pm 10$ & - & - & $1.0 \pm 0.8$ & $3 \pm 1.0$ \\
\hline $\begin{array}{l}\text { Hemothorax evacuation + } \\
\text { washout }\end{array}$ & 11 & 85 & $350 \pm 125$ & - & $2(18 \%)$ & $3.5 \pm 1.7$ & $7 \pm 3.2$ \\
\hline Bullectomy + pleurodesis & 34 & 80 & $55 \pm 10$ & - & - & $3 \pm 1.0$ & $3 \pm 1.4$ \\
\hline Decortication & 25 & 126 & $350 \pm 110$ & - & $7(28 \%)$ & $5 \pm 2.5$ & $7 \pm 4.2$ \\
\hline Wedge resection & 6 & 60 & $50 \pm 11$ & - & - & $1.5 \pm 0.9$ & $3 \pm 0.8$ \\
\hline Segmentectomy & 9 & 170 & $100 \pm 21$ & 4 & - & $2.4 \pm 1$ & $3 \pm 1.1$ \\
\hline \multicolumn{8}{|l|}{ Lobectomy } \\
\hline Aspergilloma & 9 & 244 & $315 \pm 120$ & 4 & $1(11 \%)$ & $6.8 \pm 4$ & $7 \pm 3.9$ \\
\hline NSCLC & 13 & 201 & $120 \pm 53$ & 20 & $2(15 \%)$ & $3.5 \pm 2.2$ & $4 \pm 1.5$ \\
\hline Lung Sequester & 2 & 180 & 65 & - & - & 2.0 & 3 \\
\hline Metastastectomy & 4 & 120 & $70 \pm 2$ & - & - & 2.1 & $3 \pm 1.1$ \\
\hline Bronchoplasty & 2 & 320 & 250 & - & - & 4.0 & 5 \\
\hline Thymectomy & 25 & 147 & $100 \pm 22$ & 3 & $3(12 \%)$ & $2.1 \pm 1.1$ & $3 \pm 1.8$ \\
\hline Diaphragmatic plication & 6 & 130 & $80 \pm 4$ & - & $1(16 \%)$ & $2.8 \pm 1.9$ & $4 \pm 2.1$ \\
\hline Ectopic thyroidectomy & 3 & 100 & $60 \pm 12$ & - & - & 2 & $3 \pm 1.4$ \\
\hline Ectopic parathyroidectomy & 3 & 120 & $20 \pm 3$ & & & 2 & $3 \pm 1.2$ \\
\hline $\begin{array}{l}\text { Mediastinal mass excision } \\
\text { (non-thymus) }\end{array}$ & 5 & 115 & $100 \pm 18$ & - & $1(20 \%)$ & $1.5 \pm 0.7$ & $3 \pm 2.2$ \\
\hline Pericardial window & 2 & 30 & 10 & - & - & 3 & 6 \\
\hline Chest wall resection & 1 & 105 & 100 & - & - & 2 & 3 \\
\hline Total & 169 & & & & $17(10 \%)$ & & \\
\hline
\end{tabular}

Categorical variables were reported as frequency counts and percentages. Continuous variables were reported as means and standard deviation. NSCLC: non-small cell lung cancer; U-VATS: uniportal video assisted thoracoscopic surgery

Table 3. Comparison of U-VATS procedures performed in the 1st and 2 nd year

\begin{tabular}{|c|c|c|c|c|c|c|c|c|c|c|c|c|c|c|}
\hline \multirow{2}{*}{$\begin{array}{l}\text { Procedures } \\
\text { Year }\end{array}$} & \multicolumn{2}{|c|}{ Number } & \multicolumn{2}{|c|}{$\begin{array}{l}\text { Surgery time } \\
\text { (min) }\end{array}$} & \multicolumn{2}{|c|}{ Blood loss $(\mathrm{mL})$} & \multicolumn{2}{|c|}{$\begin{array}{l}\text { Lymph } \\
\text { nodes }\end{array}$} & \multicolumn{2}{|c|}{$\begin{array}{l}\text { Conversion to } \\
\text { open thoracotomy }\end{array}$} & \multicolumn{2}{|c|}{$\begin{array}{c}\text { Drain duration } \\
\text { (days) }\end{array}$} & \multicolumn{2}{|c|}{$\begin{array}{l}\text { Hospital stay } \\
\text { (days) }\end{array}$} \\
\hline & 1 & 2 & 1 & 2 & 1 & 2 & 1 & 2 & 1 & 2 & 1 & 2 & 1 & 2 \\
\hline $\begin{array}{l}\text { Bullectomy + } \\
\text { pleurodesis }\end{array}$ & 18 & 16 & $90 \pm 22$ & $80 \pm 12$ & $52 \pm 24$ & $58 \pm 20$ & - & - & - & - & $3.0 \pm 1.0$ & $3.0 \pm 0.9$ & $3 \pm 1.0$ & $3.0 \pm 0.9$ \\
\hline $\begin{array}{l}\text { Lobectomy } \\
\text { Aspergilloma }\end{array}$ & 3 & 6 & $260 \pm 50$ & $236 \pm 35$ & $380 \pm 95$ & $283 \pm 102$ & 2 & 2 & 1 & - & $7.6 \pm 4.0$ & 6.4 & $7.6 \pm 4$ & $06.4 \pm 4.3$ \\
\hline NSCLC & 5 & 8 & $219 \pm 47$ & $190 \pm 25$ & $130 \pm 44$ & $114 \pm 31$ & $19 \pm 3$ & $321 \pm 5$ & 2 & - & $4.4 \pm 1.9$ & 3.2 & $4.8 \pm 1 . \varepsilon$ & $83.5 \pm 0$ \\
\hline Lung sequester & 1 & 1 & 170 & 190 & 60 & 70 & - & - & - & - & 2 & 3 & 2 & 3 \\
\hline Thymectomy & 11 & 14 & $170 \pm 33$ & $129 \pm 25$ & $110 \pm 15$ & $92 \pm 22$ & - & 3 & 3 & - & $2.5 \pm 1.0$ & $1.8 \pm 1.0$ & $3.3 \pm 2$ & $02.8 \pm 1.0$ \\
\hline
\end{tabular}

Categorical variables were reported as frequency counts and percentages. Continuous variables were reported as mean and standard deviation. There was no significant difference $(P>0.05)$ for the variables between the 1 st and 2 nd year for all procedures. NSCLC: nonsmall cell lung cancer; U-VATS: uniportal video assisted thoracoscopic surgery

Only 13 cases of lobectomies for NSCLC were performed by U-VATS in throughout the study duration of two years. The average time taken was $201 \mathrm{~min}$ and this includes complete lymphadenectomy of stations 2, 4, 7, 8 and 9 on the right, and 5, 6, 7, 8 and 9 on the left. In the first year of performing U-VATS lobectomies, the mean time taken was $219 \mathrm{~min}$ and this reduced to $190 \mathrm{~min}$ in the second year with no significant difference between them. The lymph node yield was at the average of 20 lymph nodes with no significant difference between the lobectomies performed in the first and second year [Table 3].

\section{DISCUSSION}

Thoracoscopic surgery has been performed via multiple access ports in the thorax since the 1990s. Many publications are available to support the efficacy of this approach ${ }^{[3-7]}$. The recently concluded randomised control trial, Video Assisted Thoracoscopic Lobectomy Versus Conventional Open Lobectomy for Lung Cancer (VIOLET) study confirmed that VATS is not inferior to open thoracotomy in the oncological outcomes of NSCLC resection and provides better post-operative pain control. Since 2003, Prof Gaetano 
Rocco from Italy has evolved from using three to two and now, a single port for thoracic surgery, performing mediastinal biopsies, wedge resections and bullectomies ${ }^{[8]}$. In 2010, Diego Gonzales Rivaz was the first to perform a lobectomy through the uniportal approach and went on to execute complex lung resections over the next few years, including carinal resections ${ }^{[2]}$. Perna et al ${ }^{[9]}$ then performed a randomised trial comparing U-VATS and multiportal VATS procedures in 2016 and found no difference in post-operative pain and analgesia intake, duration of chest drain and length of hospital stay. In the meta analysis by Abouarab et al. ${ }^{[7]}$, it was demonstrated that U-VATS provides superior post-operative outcomes over multiportal VATS.

The advantages of U-VATS are mainly seen in positioning of the videoscope in the utility port to provide an end on view to the surgeon, similar to open surgery. Insertion of instruments parallel to the videoscope also simulates the manner of dissections done in open surgery. Having all instruments inserted via a single incision also reduces post-operative pain by reducing the number of ports and prevents compression of the intercostal nerves by not using thoracoports ${ }^{[4,10]}$. Nevertheless, the crowding of instruments inserted through the same port can be an obstacle ${ }^{[11]}$. The usage of curved instruments of variable length inserted at different angles can prevent this. Thinner instruments designed specifically for U-VATS allow up to four instruments to be inserted with the videoscope ${ }^{[1,4]}$ [Figure $\left.1 \mathrm{~A}\right]$.

The thoracic unit in HKL was established in July 2017. Thoracic surgeons in Malaysia have vast exposure in laparoscopic surgeries during general surgery training and with this experience, performing VATS becomes easier. In our unit, we perform around six to seven thoracic surgeries a week with almost half performed by U-VATS and the rest were open thoracotomies. No multiportal VATS were performed, hence we are unable to compare with these methods. In our unit, surgeons must be familiar with open thoracotomy first and able to handle emergency situations such as bleeding before performing VATS.

The learning curve of U-VATS could be steeper than multiportal VATS ${ }^{[1,12]}$. Attending U-VATS workshops, attachments in high volume centres such as the Shanghai Pulmonary Hospital and watching surgical videos can assist with the improvement of developing U-VATS techniques for beginners and advanced level surgeons ${ }^{[13,14]}$. These approaches were adopted by our centre to enhance performance of U-VATS. During the learning process, we developed the U-VATS learning pyramid as a guide for trainees [Figure 2]. The U-VATS learning pyramid gradually increases the complexity of cases from the bottom up. Adapting the U-VATS learning pyramid in a stepwise manner as per the caseload in the centre may allow the learning experience to be smoother and safer for both the patient and the surgeon alike. The initial U-VATS cases that were performed were less complex, such as bullectomy with pleurodesis, traumatic hemothorax evacuation, biopsies and wedge resections. The surgeon should not perform U-VATS lobectomy if he/she has not performed U-VATS wedge resections or bullectomies comfortably before. In the first three months of performing U-VATS, most cases are from the bottom of the pyramid. Attempts to perform U-VATS lobectomy were only made once familiarity with the basic procedures were achieved. This learning pattern is seen in many other centres worldwide in learning uniportal VATS ${ }^{[3-5]}$.

The effectiveness of the learning pyramid for U-VATS is reflected in our centre having no mortalities in 169 cases performed so far. Although there was no significant difference between cases performed in the first and second year, the duration of surgery appeared to be less for cases in the second year group. This could be due to increased familiarity with handling of instruments and positioning of the camera as more cases are performed. Liu et al. ${ }^{[14]}$ showed that a minimum of 30 cases of U-VATS lobectomy are needed to reach performance plateau.

Our first uniportal lobectomy performed was a left lower lobectomy for lung adenocarcinoma with a nodule measuring $3 \mathrm{~cm}$, however an assistant port was inserted halfway through surgery for retraction 


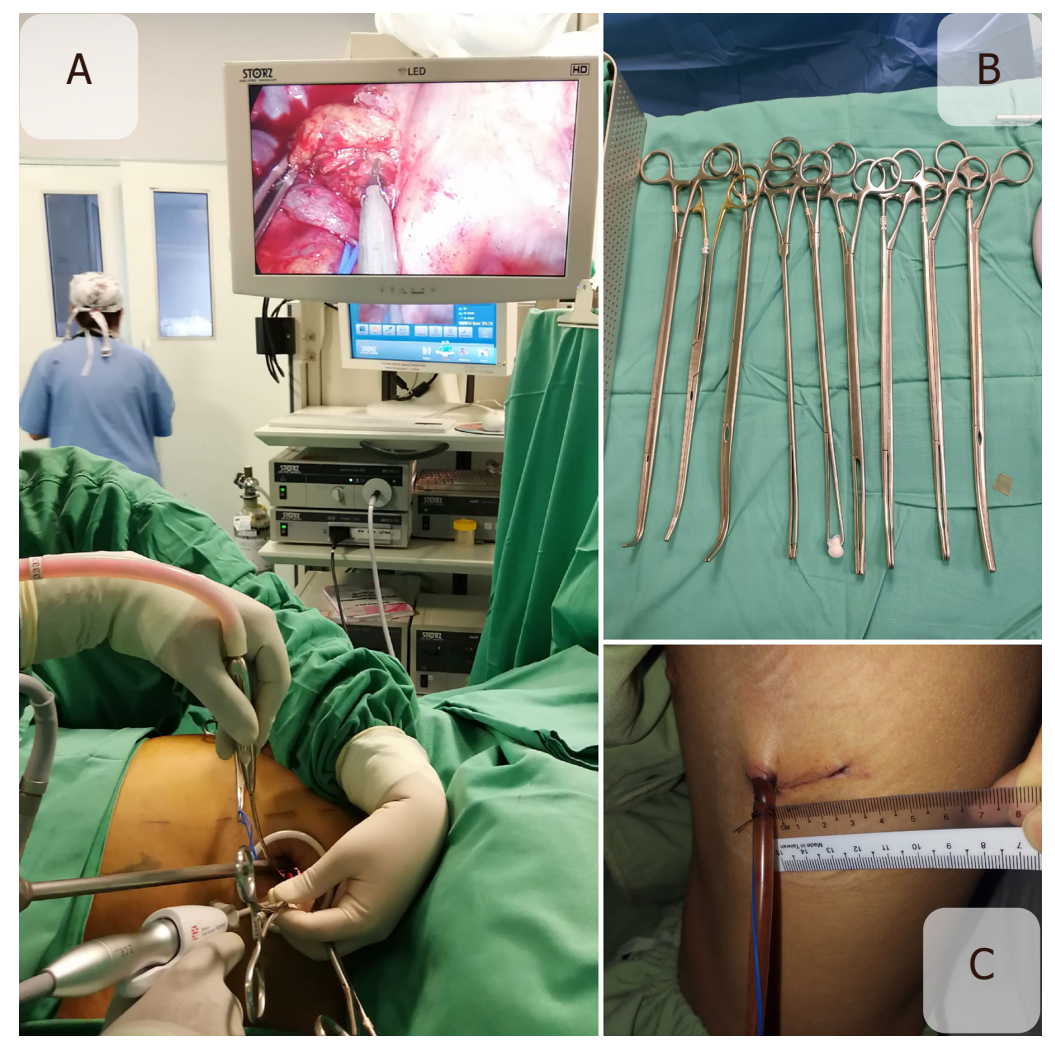

Figure 1. A: the U-VATS method of performing thoracic surgery where multiple VATS instruments are inserted through the same port to complete the resection; B: U-VATS instruments that are long and double hinged; C: the wound size for a U-VATS left upper lobectomy. U-VATS: uniportal video assisted thoracoscopic surgery

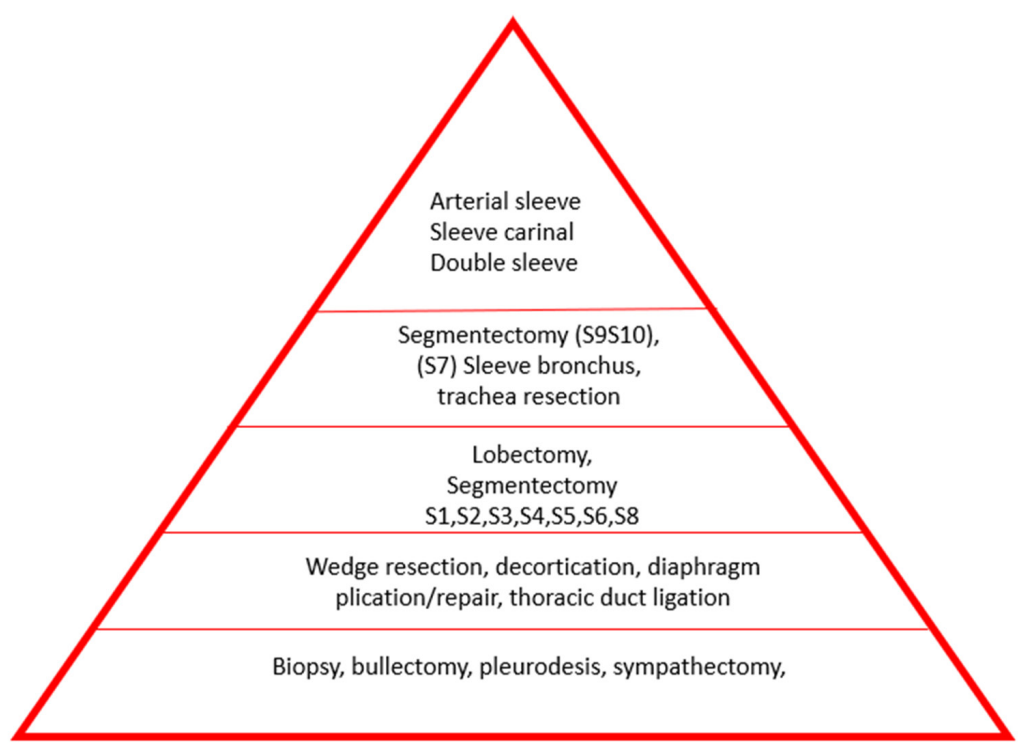

Figure 2. Suggested uniportal video assisted thoracoscopic surgery learning pyramid for adaptation in training

during lymph node dissection. It was a successful surgery that took us $200 \mathrm{~min}$ to complete. Subsequent lobectomies were performed without the assistant port. Left lower lobectomy was chosen as our first case to perform because it is easier compared to other lobes ${ }^{[1]}$. In 17 cases $(10 \%)$, we used either an extra port or converted to a mini-thoracotomy due to bleeding, to facilitate retraction or dissection, introduction of 
a stapler, completion of lymph node dissection and in some cases, enlargement of the wound to deliver the resected specimen in one piece. Ismail et al. ${ }^{[3]}$ from Germany also reported operating times of around $250 \mathrm{~min}$ in their early experience of performing U-VATS for lobectomy.

The average lymph node yield in our U-VATS lobectomy for NSCLC was 20 and this allows adequate staging assessment by the oncologist to decide on adjuvant treatment. This was similarly reported by the Koreans in their midterm outcome of U-VATS for lung cancer ${ }^{[5]}$. Crucially, one must not hesitate to introduce a second port during lymph node dissection to achieve adequate yield in the early stages of performing U-VATS lobectomy. Oncological outcomes supersede any chosen approach.

The duration of drain placement usually coincides with the length of hospital stay. Most non-infective cases were discharged by POD 3 or 4 after surgery whereas the infective cases stayed longer. The infective cases also had a higher amount of blood loss compared to lung cancer cases because of the higher degree of adhesion and inflammation and thus, the tendency to bleed more. Compared to open thoracotomy however, the blood loss difference is not significant ${ }^{[15]}$.

Within two years of performing U-VATS, we have gradually increased the complexities of the surgeries, taking care to minimise morbidities. In the last 6 months, we have performed a left segment 9 and 10 resection for a metastatic lung nodule, and a right upper bronchial sleeve resection for a right main bronchus mucoepidermoid carcinoma successfully. These cases were performed after more than 100 U-VATS cases were logged.

This review was for the first two years since setting up the thoracic surgical services in HKL. We have had a small number of patients involving all procedures, malignant and non-malignant alike. A subsequent review of patients with NSCLC with larger numbers at the 5-year mark will shed clearer light on the advantages of U-VATS in HKL, Malaysia.

\section{CONCLUSION}

U-VATS is a promising, alternative approach which is fast gaining popularity amongst thoracic surgeons worldwide. The learning of U-VATS procedures should be in a stepwise manner as suggested in our learning pyramid. Patient safety and oncological principles must always be adhered to in any form of surgery and failing to do so will require an alternative approach. The U-VATS technique may be safely adopted in a new thoracic centre if such a stepwise learning method is enforced.

\section{DECLARATIONS}

\section{Authors' contributions}

Collected and selected articles: Sathiamurthy N

Participated in manuscript, writing and review: Sathiamurthy N, Diong NC, Dharmaraj B

Participated in reviewing: Sathiamurthy N, Dharmaraj B

\section{Availability of data and materials}

Not applicable.

\section{Financial support and sponsorship}

None.

\section{Conflicts of interest}

All authors declared that there are no conflicts of interest. 


\section{Ethical approval and consent to participate}

Approval obtained from the Director's office and the hospitals' ethics committee to proceed with this analysis.

\section{Consent for publication}

Not applicable.

\section{Copyright}

(c) The Author(s) 2020.

\section{REFERENCES}

1. Gonzalez-Rivas D, Fieira E, Delgado M, Mendez L, Fernandez R, et al. Evolving from conventional video-assisted thoracoscopic lobectomy to uniportal: the story behind the evolution. J Thorac Dis 2014;6:S599-S603.

2. Gonzalez-Rivas D, Fieira E, Delgado M, Torre M, Mendez L, et al. Uniportal video-assisted thoracoscopic sleeve lobectomy and other complex resections. J Thorac Dis 2014;6:S674-S681.

3. Ismail M, Helmig M, Swierzy M, Neudecker J, Badakhshi H, et al. Uniportal VATS: the first German experience. J Thorac Dis 2014;6:S650-S655.

4. Wang L, Liu D, Lu J, Zhang S, Yang X. The feasibility and advantage of uniportal video-assisted thoracoscopic surgery (VATS) in pulmonary lobectomy. BMC Cancer 2017;17:75.

5. Han KN, Kim HK, Choi YH. Midterm outcomes of single port thoracoscopic surgery for major pulmonary resection. PLoS ONE 2017; 12:e0186857.

6. Bourdages-Pageau E, Vieira A, Lacasse Y, Figueroa PU. Outcomes of uniportal vs multiportal video-assisted thoracoscopic lobectomy. seminars in thoracic and cardiovascular surgery 2019; Article in Press, Corrected Proof. Available from https://https://www. semthorcardiovascsurg.com/article/S1043-0679(19)30170-4/fulltext [Last accessed on 8 Jun 2020]

7. Abouarab AA, Rahouma M, Kamel M, Ghaly G, Mohamed A. Single versus multi-incisional video-assisted thoracic surgery: a systematic review and meta-analysis. J Laparoendosc Adv Surg Tech A 2018;28:174-85.

8. Rocco G, Martucci N, Manna C L, Jones DR, Luca GD, et al. Ten-year experience on 644 patients undergoing single-port (uniportal) video-assisted thoracoscopic surgery. Ann Thorac Surg 2013;96:434-8.

9. Perna V, Carvajal AF, Torrecilla JA, Gigirey O. Uniportal video-assisted thoracoscopic lobectomy versus other video-assisted thoracoscopic lobectomy techniques: a randomized study. Eur J Cardiothorac Surg 2016;50:411-5.

10. Nachira D, Meacci E, Ismail M, Gonzalez-Rivas D, Margaritora S. Why change from multiportal to uniportal VATS? Video-assist Thorac Surg 2018;3:14.

11. Augustin F, Schmid T. A word of caution — when uniportal VATS should not be done. J Vis Surg 2018;4:29.

12. Sihoe ADL. Uniportal lung cancer surgery: state of the evidence. Ann Thorac Surg 2019;107:962-72.

13. Bedetti B, Bertolaccini L, Solli P, Scarci M. Learning curve and established phase for uniportal VATS lobectomies: the Papworth experience. J Thorac Dis 2017;9:138-42.

14. Liu X, ChenX, Shen Y, Wang H, Feng M, et al. Learning curve for uniportal video-assisted thoracoscopic surgery lobectomy—results from 120 consecutive patients. J Thorac Dis 2018;10:5100-107.

15. Laohathai S, Attanawanich S, Ngodngamtaweesuk M, Samankatiwat P, Cherntanomwong P. Video-assisted thoracoscopic surgery in bacterial empyema thoracic result from developing country based on Thailand experience. J Vis Surg 2019;5:7. 